\title{
ADAPTAÇÃO DO JOGO DE BOLICHE: UM RECURSO DE TECNOLOGIA ASSISTIVA A UM ESTUDANTE COM DEFICIÊNCIA MÚLTIPLA
}

\author{
Franciele Aparecida dos Santos Felicio ${ }^{1}$, Manoel Osmar Seabra Junior ${ }^{2}$ \\ 1 Graduada na Licenciatura em Educação Física pela Universidade Estadual Paulista - UNESP, Presidente Prudente, SP. E-mail: \\ fran.aparecida90@hotmail.com; Agência de fomento: FAPESP \\ ${ }^{2}$ Doutor em Educação pela Universidade Estadual Paulista - UNESP/Marília. Professor do Departamento de Educação Física e do Programa de Pós- \\ Graduação em Educação da Universidade Estadual Paulista - UNESP, Presidente Prudente, SP.
}

\section{RESUMO}

Esse artigo remete a adaptação de estratégias e de um recurso pedagógico em um contexto de ensino e aprendizagem, na perspectiva lúdica, de capacidades e habilidades a um estudante com deficiência Múltipla. O objetivo central deste estudo foi adaptar o jogo, elaborar, descrever e analisar estratégias de ensino no boliche, como um recurso de Tecnologia Assistiva para aquisição e/ou aprimoramento de habilidades e capacidades motoras. Como procedimento utilizou-se de relatório de campo e filmagem. Foram necessarias 25 sessões para obtenção de um feedback para análise das diferentes situações do jogo. O jogo escolhido foi o boliche convencional, no qual o pesquisador adaptou os elementos do jogo; como bolas, pinos, pista, e as estrategias de ensino (modo de lançar e localização dos pinos), necessários frente a condição funcional do participante.

Constatou-se que as adaptações realizadas no jogo, e as estrategias, foram suficientes para atender o objetivo.

Palavras-chave: Tecnologia Assistiva. Deficiência Múltipla. Boliche adaptado. Jogo de mesa. Estratégias de Ensino.

\section{ADAPTED BOWLING: AN ASSISTIVE TECHNOLOGY RESOURCE FOR A STUDENT WITH MULTIPLE DISABILITIES}

\section{ABSTRACT}

The article discusses adapted strategies and a pedagogical resource in the context of a ludic approach to teaching and learning and of capacities and abilities of a student with Multiple Disabilities. The main objective of the study was to adapt the game, elaborate, describe and analyze pedagogical strategies in bowling as an Assistive Technology resource for acquiring and/or improving the abilities and motor. Field notes and video recording were used as data. Twenty-five sessions were necessary for obtaining feedback and analyzing the different situations in the game. The focus of the adaptation was conventional bowling, in which the researcher adapted the following elements of the game: balls, pins, the lane itself, as well as teaching strategies for the game (such as rolling technique and pin placement), necessary for meeting the participant's functional condition. It was verified that the adaptations made in the game, as well as the strategies, were sufficient to meet the expected goal.

Keywords: Assistive Technology. Multiple Disabilities. Adaptive bowling. Board game. Pedagogical Strategies.

\section{INTRODUÇÃO}

Este artigo apresenta um relato de pesquisa com um participante com deficiencia multipla. Este participante, já investigado em outros estudos destes mesmos autores, caracteriza-se como um estudante do ensino fundamental, com a associação da cegueira e da paralisia cerebral (PC), denominando-se Deficiencia Multipla (DM), ambas em condições congenitas. Essasdeficiências acarretam prejuízos físicos e sensoriais, consequentemente restrições na ação motora e no feedback.

A Deficiência Múltipla refere-se à associação de duas ou mais deficiências; e com mobilidade reduzida, que gera redução de flexibilidade, coordenação motora e percepção, conforme definido no Decreto no 5.296, Art.5은 Inciso II (BRASIL, 2004).

O participante selecionado neste estudo é integrante de um projeto de pesquisa junto ao 
LETAIA - Laboratório de Pesquisa e Estudos em Tecnologia Assistiva, Inclusão e Adaptação, da FCT, UNESP de Presidente Prudente. O jogo de boliche, que ora se apresenta neste estudo, é o segundo jogo que é adaptado ao mesmo participante, além de outros oito brinquedos que já foram adaptados por meio de estudo experimental, utlizando o delineamento intrassujeitos. Cada jogo tem suas características próprias além da exigência de movimentos diferenciados, o que não gerou a influência de variáveis intervenientes no processo de ensino que tenha indicado que o participante já tenha experiência ou movimento próprio, que não requeira qualquer adaptação do movimento ou do recurso.

Este jogo de Boliche foi selecionado por apresentar uma caracteristica de competitividade, e, ao mesmo tempo, de ludicidade. Desse modo surgiu a ideia de adaptar um jogo que trouxesse desafios e que estimulasse habilidades manuais, com o objetivo de criar estrategias que potencializasse o desempenho do participante em quaisquer jogos, de forma com que as aquisições, deste meio, sejam resultados de suas conquistas para independência de atividades de vida diária.

Para Grando (2004, p.31):

0 jogo favorece 0 desenvolvimento da criatividade, do senso crítico, da participação, da competição "sadia", da observação, das várias formas de uso da linguagem e do resgate do prazer em aprender

Não obstante, surgiu a possibilidade do boliche, por ser um jogo em que o participante demonstrou interesse e que atende as características em relação ao desenvolvimento de habilidades manuais, cognitivas entre outras psicomotoras.

Estudiosos como Kishimoto, resaltam que trabalhar com o boliche nas fases iniciais da vida proporciona:
Trabalhar o boliche com uma criança com deficiencia multipla, que na maioria das vezes não passou por essas fases, implica na necessidade de adapatações para que ele possa superar suas limitações, consequentemente oportunidades iguais para o jogo em relação ao adversário, configurando este como um recurso de Tecnologia Assistiva.

Segundo o Comitê de Ajudas Técnicas (CAT - Comitê de Ajudas Técnicas, 2007, p. 26), Tecnologia Assistiva é:

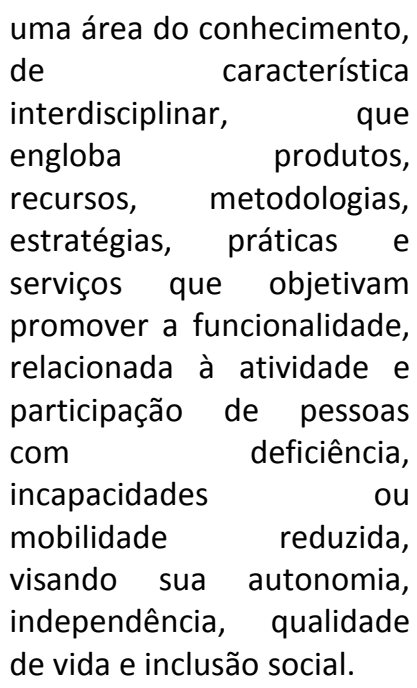

Contudo, o objetivo deste estudo foi adaptar o jogo de boliche a um estudante com deficiência múltipla com enfoque no desenvolvimento das habilidades manuais necessárias na atividade de vida diária.

\section{METODOLOGIA Tipologia de Estudo}

Esse estudo optou pela técnica da observação participante e descritiva, onde o pesquisador pode agir diretamente na intervenção e age como mediador.

Minayo (2004, p. 59) explica que:

A técnica da observação
participante se realiza
através do contato direto
do pesquisador com o
fenômeno observado para
obter informações sobre a
realidade dos atores sociais
em seu próprio contexto...
Nesse processo, ele, ao
mesmo tempo, pode
modificar e ser modificado
pelo contexto. A
importância dessa técnica
reside no fato de podermos
captar uma variedade de
situações ou fenômenos 
que não são obtidos por meio de perguntas... transmitem o que há de mais ponderável e evasivo na vida real.

Assim como a descritiva tem a função de apresentar características, dos mais variados tipos, seja em relação à de população, fenômenos que os envolvem ou experiências, constituindo uma relação entre essas variáveis e o objeto de estudo analisado (THIOLLENT, 1986).

\section{Procedimentos para Coleta de Dados}

O participante selecionado para a pesquisa foi um estudante do sexo masculino, matriculado na rede estadual de ensino, mais especificamente no 70 ano do ensino fundamental II, com 13 anos de idade, diagnosticado com Deficiência Múltipla, no caso a associação da Paralisia Cerebral, mais especificamente a encefalopatia crônica não progressiva (diparesia espástica) e cegueira congênita.

Os atendimentos ocorreram semanalmente, no interior do LETAIA, em uma sala especifica, totalizando 25 sessões de uma hora de duração. O participante permaneceu na cadeira de rodas, equipamento que não impediu sua mobilidade para a ação do arremesso.

Em cumprimento aos preceitos éticos, foi coletada a assinatura dos responsáveis no Termo de Consentimento Livre e Esclarecido (TCLE), conforme a Resolução 466/12 do Conselho Nacional de Saúde (CNS), e do Termo de fotografia e filmagem, os responsáveis pelo estudante, autorizaram sua participação, que se encontra registrado sob o CAEE 951.774, do Comitê de Ética de Pesquisa (CEP).

Foi realizado com o estudante dois testes para avaliar o nível da motricidade grossa e fina. $O$ primeiro consistiu em um roteiro de entrevista, com o intuito de avaliar a habilidade manual dos estudantes (MACS). O segundo refere-se a função motora grossa da GMFCS.

Os níveis do MACS que possui cinco níveis desde manipular objetos facilmente até não manipular os objetos .O participante foi classificado no nível II, quando consegue manipular os objetos mas apresenta dificuldades na velocidade e precisão do movimento.

Os níveis gerais do GMFCS são: I. Anda sem limitações; II. Anda com limitações; III. Anda utilizando um dispositivo manual de mobilidade; IV. Auto mobilidade com limitações; pode utilizar mobilidade motorizada; V. Transportado em uma cadeira de rodas manual. Pois bem, por meio da indicação das terapeutas, o participante foi classificado no nível $\mathrm{V}$, utiliza de cadeiras de rodas para locomoção.

O jogo selecionado para adaptação foi o Boliche. O critério para seleção do jogo considerou interesses do participante quanto à ludicidade, mas, sobretudo, necessidades de desenvolver competências manuais que capacitem o mesmo em atividades de vida diária.

A adaptação inicial do boliche consistiu dos seguintes materiais: garrafas PET de 2 litros, bolas de borracha, meias finas e grossas. A pista utilizada foi uma mesa de madeira adaptada, de aproximadamente 3 metros com regras modificadas.

\section{Procedimentos para Análise dos Dados}

Para análise foram utilizados protocolos de observações, relatórios pós atendimentos e filmagens. Nestes instrumentos foram separados os seguintes itens, por etapas de: 1 . Adaptações do jogo; 2. Competências exigidas pelo jogo; 3. Estratégias necessárias para sua aplicação; 4. Feedback do participante e 5 . Habilidades psicomotoras requeridas. Dados extraídos no bojo das 25 sessões de uma hora de intervenção. As intervenções foram filmadas e, posteriormente, redigidos os relatórios pós-atendimentos.

Estes diferentes dados serviram para pontuar eixos de discussões sobre: a relevância do jogo, a possibilidade de ter este recurso como uma tecnologia Assistiva e, por fim, um contributo para estimular a realização de suas atividades de vida diária com independência.

\section{RESULTADOS}

Para se alcançar os resultados obtidos foram necessárias 25 sessões para que o participante fizesse com precisão os movimentos, obtivesse uma melhor concepção do jogo e, ainda, emitisse um feedback positivo com este recurso.

Os resultados obtidos com a adaptação do jogo de boliche foram favoráveis ao participante, que demonstrou maior domínio nas habilidades requeridas, consequentemente no desempenho com o jogo.

Na Quadro 1, é apresentada a descrição do jogo convencional e do jogo adaptado de boliche, ressaltando suas características originais e com adaptações. 
Quadro 1. Adaptações no jogo do Boliche segundo sua características originais

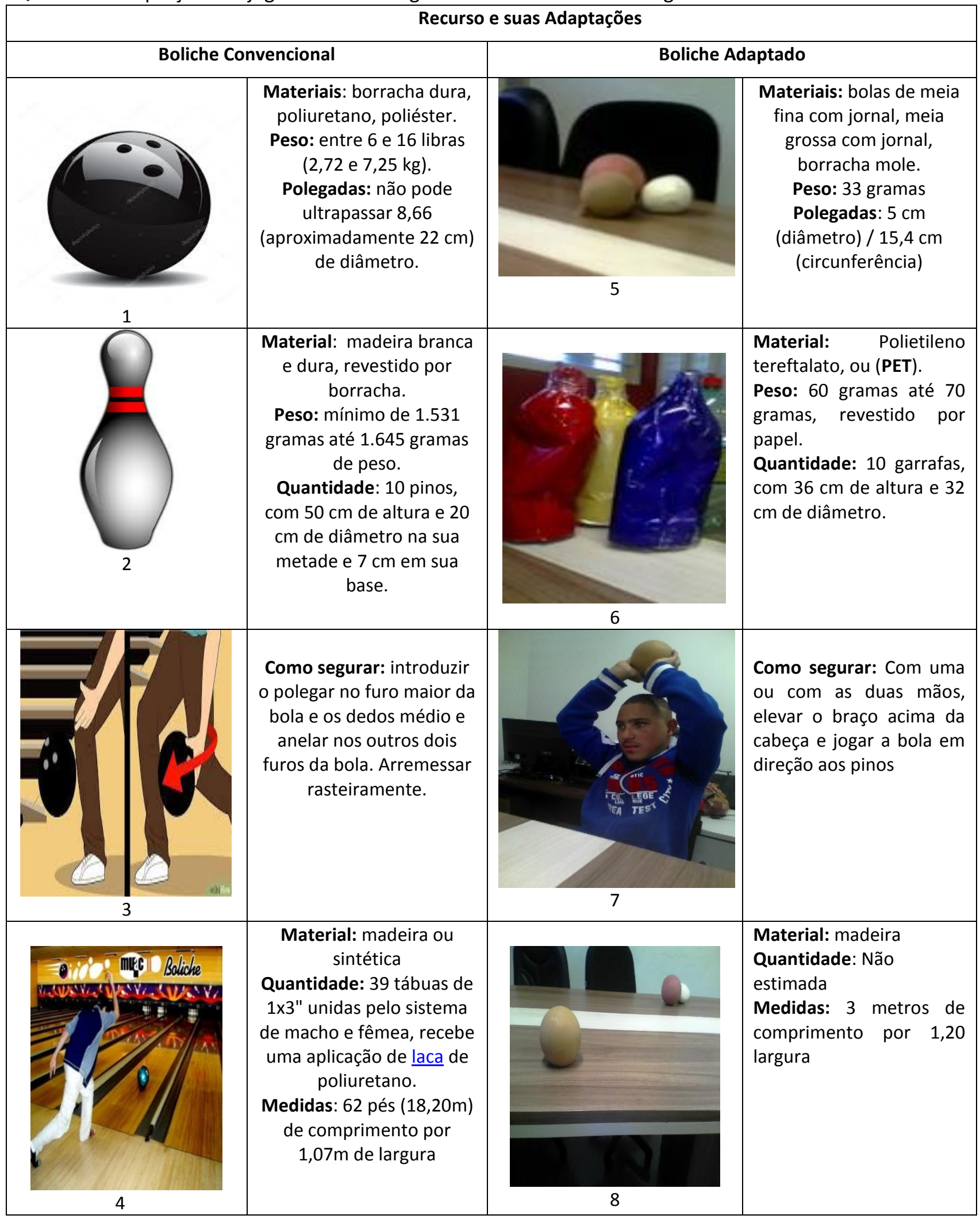

Figura 1: Disponivel em: https://pt.depositphotos.com/4601267/stock-illustration-bowling-ball-set-1.html;Figura 2: Disponível em: https://pixabay.com/pt/boliche-pinos-esportes-jogos-158421/;Figura 3: Disponível em: http://pt.wikihow.com/Jogar-Uma-Bola-de-Boliche-Com-;Figura4:Disponívelem:

Curvahttps://pt.wikipedia.org/wiki/Boliche; Figura5,6,7,8: arquivo pessoal do pesquisador

Pode-se notar que existem diferenças do jogo convencional para o adaptado, mas mantendo-se o mesmo intuito do jogo. Para que o participante com deficiência múltipla pudesse desempenhar o jogo de modo satisfatório, não omitindo os princípios do jogo em questão, foi necessário adaptar e utilizar de estratégias que possibilitassem sua participação. 
Adaptações essas apresentadas no quadro 1 , com materiais de baixo custo, ou até mesmo reciclável. Durável, de fácil manuseio, compreensão dele e até mesmo de seus familiares e de fácil aquisição ou confecção com cores estimulantes, caso o participante tenha algum resíduo visual, condições estas que geraram um excelente feedback.
No início o participante apresentou dificuldades com as bolas mais leves, mas no decorrer das intervenções possibilitou aprimorar o movimento, tendo um feedback positivo.

$\mathrm{Na}$ Quadro 2, estão destacadas as principais estratégias utilizadas para a execução do jogo propriamente dito e a descrição dos momentos em que as competências e habilidades foram estimuladas durante o jogo.

Quadro 2. Estratégias e habilidades desenvolvidas segundo cada etapa do jogo.

\begin{tabular}{|c|c|c|}
\hline Etapas & Estratégias & $\begin{array}{c}\text { Avanço no desempenho das } \\
\text { habilidades }\end{array}$ \\
\hline $1^{0}$ Localização dos Pinos & $\begin{array}{l}\text { Para que o participante localizasse os } \\
\text { pinos, foram feitos estímulos } \\
\text { sonoros,(palmas), primeiramente } \\
\text { nos últimos pinos e no central, } \\
\text { sendo requerido lançar a bola no } \\
\text { estimulo central, para que } \\
\text { conseguisse o objetivo do jogo, o } \\
\text { straike. }\end{array}$ & $\begin{array}{l}\text { - } \text { Orientação Espacial. } \\
\text { - } \text { Tempo de resposta } \\
\text { - } \text { Agilidade } \\
\text { - } \text { Coordenação }\end{array}$ \\
\hline $\begin{array}{c}2{ }^{0} \text { Modo de Lançar a } \\
\text { bola }\end{array}$ & $\begin{array}{l}\text { A bola foi lançada começando pela } \\
\text { mais pesada (borracha), em seguida } \\
\text { com as demais, sendo a de meia } \\
\text { grossa, seguida da meia fina. } \\
\text { Primeiro com uma mão depois com } \\
\text { as duas, sendo posicionada a mão } \\
\text { acima da cabeça para realizar o } \\
\text { lançamento. }\end{array}$ & $\begin{array}{l}\text { - Habilidades manipulativas, } \\
\text { - Motricidade grossa } \\
\text { - Motricidade fina } \\
\text { - } \text { Coordenação }\end{array}$ \\
\hline $\begin{array}{l}3^{0} \text { Posicionamento do } \\
\text { participante }\end{array}$ & $\begin{array}{l}\text { O participante foi posicionado no } \\
\text { centro da mesa, onde foi requerido } \\
\text { que ele fizesse primeiramente o } \\
\text { reconhecimento do espaço de modo } \\
\text { a facilitar sua mobilidade para fazer } \\
\text { os lançamentos da bola. }\end{array}$ & $\begin{array}{l}\text { - Senso de direção } \\
\text { - } \quad \text { Localização do espaço }\end{array}$ \\
\hline $4^{0}$ Local de arremesso & $\begin{array}{l}\text { A mesa foi escolhida, por } \\
\text { inicialmente ter tido uma tentativa } \\
\text { de fazer no chão, mas que acabava } \\
\text { não tendo um bom rendimento pela } \\
\text { falta de mobilidade das pernas do } \\
\text { participante, e na mesa ele tem o } \\
\text { controle de tronco, além de estar na } \\
\text { altura de seus membros superiores. }\end{array}$ & $\begin{array}{ll}\text { - } & \text { Melhora da força } \\
\text { - } & \text { Precisão de movimento } \\
\text { - } & \text { Flexibilidade } \\
\text { - } & \text { Força abdominal } \\
\text { - } & \text { Autoconfiança }\end{array}$ \\
\hline
\end{tabular}

Em relação às estratégias e as habilidades desempenhadas denota-se que houve um progresso na coordenação motora, força e precisão de movimentos, apesar do participante apresentar dificuldades motoras, decorrente da deficiência. Por meio das estratégias e da sistematização do jogo ele conseguiu executar o objetivo geral que o jogo traz, alcançando por diversas vezes consecutiva o a pontuação total (straik).
Ainda nos momentos de dificuldades nas habilidades para executar o movimento, o participante se manteve motivado e entusiasmado a alcançar seus objetivos, o que foi preponderante para atingir suas metas.

O número de sessões para que fosse alcançado o objetivo foi de grande importância para a conquista dos resultados alcançados, uma vez que é necessária uma constância para 
execução correta, avanço e feedback positivo nas habilidades.

\section{DISCUSSÃO}

O jogo de boliche adaptado foi selecionado visando desenvolver as funcionalidades do participante como motricidade, coordenação motora, arremesso ao alvo, controle de força, direção entre as mais variadas características presentes no jogo, e ao atender essa perspectiva vislumbra-se que este se torne um recurso de Tecnologia Assistiva. Não obstante, uma maior interação com o meio, ambiente social, concepções de atitudes, respeito, regras, características essas que o jogo traz (HAIDT, 2003)

Barbanti (2003) cita que o jogo é uma forma de competição prazerosa, sendo que o resultado é verificado por habilidades motoras, chances e estratégias. A sua utilização como recurso de Tecnologia Assistiva, pode favorecer a melhora das habilidades de estudantes com deficiência múltiplas, e sua utilização aliada a estratégias e os diferentes meios de trabalho poderá servir como auxilio. O trabalho com a adaptação requer respeito as necessidades, capacidades e limitações para o este recurso se torne uma ferramenta eficaz para o desenvolvimento da criança com deficiência múltipla.

\section{CONCLUSÃO}

A possibilidade de criar jogos que garantam maior repertório de estímulos à pessoas com deficiência remete a possibilidade do professor ter recursos de Tecnologia Assistiva específicos para cada necessidade à ser desenvolvida com seus estudantes como requisito para a aquisição de competências necessárias para o ensino ou mesmo para contribuição no processo de aperfeiçoamento de suas habilidades e/ou atividades de vida diária.

As adaptações para atender necessidade de um estudante com deficiência múltipla fez com que o pesquisador analisasse as experiências de percepção e ação do participante, e contemplasse mudanças de equipamento, ambiente, regras, posicionamentos e materiais que atendessem questões voltadas aos prejuízos físicos e sensoriais envolvidos no contexto da deficiência o que traz a luz da investigação possibilidade de sugerir experiência de contexto com o jogo antes da aplicação de qualquer adaptação, o que poderá minimizar as mudanças necessárias no jogo.

\section{REFERÊNCIAS}

BARBANTI, V. J. Dicionário de educação física e do esporte. São Paulo: Manole, 2003.

BRASIL. Decreto № 5.296, de 02 de dezembro de $2004 . \quad$ Disponível em: http://www.planalto.gov.br/ccivil 03/ ato20042006/2004/decreto/d5296.htm. Acesso em: 02 jul. 2017.

CAT - Comitê de Ajudas Técnicas. Ata da Reunião V, de agosto de 2007 do Comitê de Ajudas Técnicas. Brasília: Presidência da República, Secretaria Especial dos Direitos Humanos, 2007.

GRANDO, R. C. O jogo e a matemática no contexto da sala de aula. São Paulo: Paulus, 2004.

HAIDT, R. C. C. A interação professor-aluno. In: Didática geral. 7.ed. São Paulo: Ática, 2003. p. 7580.

KISHIMOTO, T. M. O brincar e suas teorias. São Paulo: Pioneiro Thompson Learning, 2002.

MINAYO, M. C. S. Pesquisa social. 23. ed. Petrópolis: Vozes, 2004.

BRASIL. Ministério da Educação. Secretaria de Educação Especial. Educação inclusiva: direito à diversidade. Brasília, 2005. (documento orientador). CNE.Parecer do conselho nacional de educação - câmara de educação básica (CNE/CEB 17/2001). Disponível em: <http://portal.mec.gov.br/cne/arquivos/pdf/CEBO 17_2001.pdf.

Recebido para publicação em: 09/08/2017

Revisado em: 16/08/2017

Aceito em: 15/09/2017 